\title{
WE LEARN STATISTICS AND MATHEMATICS HARDLY
}

\author{
Mohammad Nekoufar \\ Department of Mathematics and Statistics, Andimeshk Branch, Islamic Azad University, \\ Andimeshk, Iran \\ mrnekoufar@gmail.com
}

In the first session of the school year, the researcher faced this question by a student: 'why can't we learn mathematics and statistics while we can succeed in other subject matters with little amount of effort?' Of course, facing such a question was not beyond expectation; many students in Iran and other countries may ask such a question. Skamp (1976), Serpinka (1998), Freudental (1982) support this point. Based on his experience, the researcher considered Skamp's theoretical framework on schemata, and learning in structuralist viewpoint as suitable to account for this question. The student's role is regarded as vital. The research findings were put into practice in the class by the researcher, which yielded satisfactory results. The present study first gives a discussion on the students' meaningful theoretical infrastructure of the mathematical knowledge, then presents the research results.

\section{INTRODUCTION}

Learning is the most important principle in learning. Then if learning occurs, why students who have received instruction in mathematics criticize their past experience with mathematics and statistics in the beginning of school year regarding mathematics and statistics classes as boring and abhorrent? Findings of learning psychology research from cognitive perspective show that learning, in the proper sense of the word, is not a linear relationship between the stimulus and response but it is a process which has three important characteristics: a) reflective, that is flow of mind, exploring in and contemplating over it b) structural, i.e., based on cognitive structures and fundamental organization of mind, and c) self-regulatory, i.e., internal equilibration and building relationship between the learned and previously-learned matters (Witrock 1991 cited in Karimi 2002). The student of the modern age and current generation desires to construct knowledge himself or herself, so (s)he does not confirm a thing very easily. (S)he does not want to be merely a receptor of the knowledge produced by others but (s)he tries to find convincing answers to his or her own questions. The traditional education tends to transfer knowledge to students as usually passive receptors. Thus a conflict appears here, which makes the student feel bored with such instruction especially in mathematics and statistics. This boredom may even lead to the phenomenon referred to as mathematophobia, which is hatred or fear of mathematics. So, the present situation necessitates that we search for reform in mathematics and statistics classes.

The present study provided learning opportunities for most of the participating students because of the researcher's motivation, and use of challenging, pleasant activities in a way that mathematics and statistics classes under study became learning communities. This study also shows that students can learn mathematics and statistics with higher comprehension , and actively construct new knowledge based on the previous knowledge at least by using the methods applied by the researcher.

\section{THE THEORETICAL BACKGROUND REQUIRED TO EXPLAIN THE UTILIZED MECHANISMS}

In this section, two theories are presented to better analyze the mechanisms used in the present work. First, the constructivism theory is presented, which is supported by many educationists nowadays. Then, Skamp's mind schemata theory is presented to account for how learning occurs from constructivist view.

\section{CONSTRUCTIVISM THEORY}

According to Carpenter, Fennema, Franke, Levi and Empson (1999), constructivism was introduced by works by Piaget (1970), Skamp (1979), Wertheimer (1945 and 1959), and Ausubel (1968 and 1978). In this theory, contrary to behaviorism, learning is not a change in the explicit 
behavior of an individual. It is a change in an individual's cognitive structure and mental processes. Moreover, the learner is not regarded as a passive acceptor or receptor of knowledge. The learner must participate in his or her own learning in an active and constructive way. So, we can say that in this theory, passive learning is mutually exclusive (Van der wiel, 2001). In fact, the most fundamental principle of constructivism is that student create their knowledge themselves (Novak. 1986; Skamp, 1989; Antony, 1996; Isons, 2000, Van de Wiel, 2001). Thus Ramberg states that nowadays, learning is considered as constructible, learning results from active participation, and teaching is viewed as guidance ( cited in Gooya, 2000). That's why the teacher is regarded, in this theory, as one who facilitates the learning not one who transfers the knowledge (Lacrose, 1991; Gooya, 2002; SarkarArayi and Moghaddam, 2002;Rogers cite in Karimzade Naim, 2002). According to this view, the meanings created by student may be different from those intended by the teacher and in some instances incorrect. But these errors constitute a part of the process of constructing and testing the personal theory. They also indicate the nature of the learner's understanding. In addition, Herskovitch and Nashr (1996) maintain that reference to schemata in the learning theory is a constructivist approach in nature. So, it will be appropriate to study the students' mental schemata in order to describe, explain, and analyze their learning (Olivier,1992).

\section{SKAMP'S MENTAL SCHEMA}

Skamp $(1986,1989)$ considers schema as a mental structure in which students' relevant experience and knowledge are organized. He regards understanding as the accommodation of a new content into an existing schema. Thus, enabling a schema is an approach that emphasizes on linking new information to the previous knowledge so that meaningful learning can occur. According to Skamp, since a new experience that is matched to a schema can be memorized efficiently, it has a high selective effect on our experience so that most of the new knowledge that is not matched to a schema will not be learned, and if learned, it will be forgotten soon (Skamp 1986, cited in Tall, 2002). Speaking so, based on this view, learning becomes possible when causes the linking and mixing between the schemata existing in an individual's mind and new knowledge. This is of high importance in mathematics because the mathematical knowledge is built upon the previous knowledge, and there is a chain-like relation between the topics in a way that weakness in one can drastically impinge on the learner's performance in another topic. According to Skamp, schemabased learning is productive and more economical and effective due in different conditions to the numerous links it creates whereas the result of habit-based learning is just a habit-driven or instinctive response to a situation or a certain stimulus. Moreover, it can be said that in parrot-like learning, materials are not essentially linked to something or the link between them is weak. As quoted by Thomas(2002), Skamp states that in parrot-like learning, the links between the materials and notions are superficial and weak, whereas in meaningful learning, there are profound, conceptual links. Similarly, Fischbien and Cuzikant hold that we won't achieve mathematics by teaching laws and rules. We can teach the laws easily but knowing mathematics requires the possession of a group of integrated and hierarchical schemata.

\section{CLASSIFICATION OF STUDENTS' ATTITUDE}

Basically there are four categories of students with respect to their attitude toward learning:

Those who can, those who don't know, those who don' want, and those who can't. The first category includes students who do their best in any condition. The number of such students is very limited in ordinary schools. The second category includes students who lack in knowledge and awareness. The third category includes students that do not want to do any attempt to learn. They obstinately resist eagerness for learning, and are at war with the situation aimlessly. It is worth noting that a great number of these students have developed negative beliefs about their abilities due to their past failures and difficulties with mathematics and statistics understanding. The last category includes students that possess the required knowledge and awareness, are not obstinate and pertinacious, but cannot use their knowledge and skill effectively due to the secondary obstacles. The author believes that the number of second-category type students is less than five in a class with 30 students, and that most of the students fall under third and fourth categories.

In the present study, the author used the approach recommended by Bishop (2000) that is situation change because the students were motivated and asked for new teaching methodologies. 
According to Popham (2006), with change in situation, the learner is placed in a different ability level. Mathematics education holds that if the teacher or teaching methodology changes, then the learner may appear in a higher level of ability. For instance, if the teacher applies methods involving active and imaginative activities, most students will begin to perform well. Using this methodology, the author was able to tremendously increase the high-achieving students' sense of duty to do the homework, and learning enthusiasm, and make other students satisfied with the class outcomes.

\section{INITIAL MEASUREMENT}

In order to emphasize on the effect of the previous learning on students' beliefs, Thomas (cited in Sharifan, 2002) quoted Ausubel (1986) saying that if I were to summarize all the educational psychology into just a one principle, it would say that the only factor that has the most effect on learning is the learner's previous knowledge. Since in mathematics and statistics, concepts are formed in a hierarchical manner, and this characteristic makes the learning of each concept dependent on the student's understanding and conception of its prerequisite concepts, for every new topic, the author asked the students to study the prerequisite materials and answer these two questions on paper:

1. What do I know about the topic?

2. What do I want to know about the topic?

In order to answer these questions, the students had to review the materials taught in the previous grades, and take a glance at the new lesson not taught yet. They had to write the answer to each question independently on a piece of paper. Then, the researcher reviewed their written answers in each session, and made a summary of the materials of the previous years by analyzing a number of the answers with the help of students. This constituted a part of their class assessment. Then, the new topic was taught and proceeded well through the students' enthusiastic participation and questions. In this phase of the teaching-learning process, some problematic points which they couldn't understand well were made clear. This both paves the way for a better preparation to understand the new topic well, and the creation of an environment in which mathematics is not regarded as a frightening monster. The above strategy has some advantages; the teacher becomes aware of each student's previously learned knowledge of the topic, which helps him/her to recognize the correctness or incorrectness of the previous learning, and possible misunderstanding. Furthermore, recalling the previous knowledge enhances students' interest in the new topic and linking the new and previous learning. After the presentation of the instruction, students are required to design a table as follows, and summarize the lesson:

\begin{tabular}{|c|c|c|}
\hline What do I know? & What have I learned? & What do I need to know? \\
\hline & & \\
\hline
\end{tabular}

Table 1

The first column helps the teacher understand the students' previous knowledge, and become aware of their possible incorrect information. The second column helps students to review and internalize what they have leaned. The third column helps the teacher be informed about the learners' need so that he can present relevant instruction, homework, and activity.

\section{CLASS VOTING}

Class voting is a powerful method that develops active learning. It involves students directly in lessons, and can be easily applied in ordinary classes. This method doesn't allow students to be passive and inactive learners, and requires them to create an effective learning environment through class involvement. Here, we point to an instance:

Teacher: calculate the value of $\sqrt{7}-1$

The students' answers to this problem differed. The researcher began to ask the students from one side of the classroom. If the first student's answer was the same with the next one, he would circle around it meaning that this answer has been confirmed by two individuals but if the answer was different, he would write it on the board as a one more answer. This process continued until the last student answer was checked. Finally, it was made clear that how many students have 
given correct answers to the question. This process was again performed collaboratively to know which group confirms what answer. In this situation, one could observe a good example of discussion and view exchange, respecting peers' remarks, and idea expression among the students. Such a scene was really interesting to the researcher. When all the groups expressed their ideas, the teacher, if necessary, would guide the students to come up with the right answer, and again asked the groups whether their idea had changed. In many cases, it was seen that the group changed their idea, and gave the correct answer. Otherwise, the teacher himself would solve the problem. This method has many advantages, some of which are summarized as follows:

- It requires all the students to think over the problem, and come up with an idea about it, then make a decision on its solution.

- It provides the teacher with the immediate feedback that whether the students have understood the notion, or whether they need to review it. The students also receive the very same feedback about themselves.

- This technique is an effective launch pad to more fruitful class discussions. In some class discussions, students are reluctant to express their ideas because they are afraid that their answer might be incorrect. Class voting provides students with adequate time to think and decide on idea expression. Since they see other classmate vote in the same way, they often become willing to talk about their votes. Such class discussions don't allow discussions to be confined to few students, and involve a larger number of them.

- It is exciting; students enjoy the class involvement and learning free space.

- It makes it clear for the researcher when we provide the students with numerous opportunities to represent their knowledge, in fact, we encourage them to create and present personal ideas (Tobbin and Imold, 1993). Additionally, helping the student in different situation is of great importance in this method since it enables them to make the acquired knowledge meaningful, which helps them build coherent mental ideas.

\section{A NEW TECHNIQUE FOR ASSESSMENT}

Class is a social arena where numerous roles are played by different agents. Mathematics and statistics learning should be enjoyable like a challenging activity on loveable grounds. Learners cooperate, if necessary, and learn from each others' viewpoints. The following approaches which have been verified for achieving the above goals are presented:

\section{USE OF SCHEMATA}

In each session, the teacher researcher asked at least one student to draw a diagram on the board showing the relationship between the new learning with the previous knowledge. Then the teacher asked the student "have you drawn all the relationships?" Having checked the diagram, the student would answer in the affirmative, or add some new links. Then the teacher asked" Are the relationships complete?" After short time in which the students exchanged views with each other, the group representatives explained their mathematics or statistics ideas in tranquility, and drew the new links as the result of their collaboration. According to Lefrancois (1999), Smith (cited in Vern De Wiel , 2001) regards this as a step toward mathematics development . In this phase, one could see the very student regrets why he himself couldn't notice the new link. Such activities help students develop a common language to express ideas. Students who are provided with opportunities to talk, write, read, and listen in mathematics and statistics classes, and are encouraged for such activities, reap lots of benefits. They communicate for the purpose of learning mathematics and statistics, and communicate mathematically.

\section{ASSESSMENT}

In this method, when each chapter of the book was fully covered, the students had to get prepared for an exam of course not in paper-and-pencil format but collaboratively on the board. The teacher randomly selected a group member to come to the board as the group representative. This member had to take the responsibility of a part of the teaching. The students could ask him their questions, and he had to answer them. It should be noted that when students prepare themselves for presenting teaching to the class, they consider the result as belonging to the all members of the group. So, they cooperated well during the week, and tried to discuss the topic to 
teach fully. Before each session, the students asked the teacher to explain the problems they had found so that they could present a faultless teaching. Then the class activity began. The group called up to the board had to solve the exercises at the end of the chapter. The other members of the group were active during their representative's presentation, and if he possibly made a mistake, they could intervene to correct it. If the group members didn't notice their representative's mistake, other students could tell the mistake at the end of the presentation, and the group would be given a negative point. Of course, in grading the students' work, the researcher knew that this would not result in their subsequent learning in itself. For the efficacy purpose in learning, the students need the feedback that can provoke their contemplation while grade, rating or statements like ' it is ok', ' try more' does not provoke students' contemplation. It should be noticed that in grading the students' work, process-oriented approach was more dominant than product-oriented view. The feedback that shows students what they need or what to do in order to improve their learning can provoke their contemplation. This methodology was so useful that I like to call it ' catalytic method'. This assessment was a kind of collaboration and participation in which the students can develop a common language for educational description and analysis and teaching each other about education through collaborative work for improving both their learning and mark. Another good point of this methodology is that both teaching and assessment welcome the collaborative learning and participation of the learners. The researcher tried to design a setting that extend the psychological and pedagogical fundaments of teaching to assessment. The author holds that unity in the educational psychology and teaching pedagogy of a class is of great importance. It can be counter-productive to have, for instance, a cognitive teaching setting but a behavioristic assessment.

\section{CONCLUSION}

As we noted above, most of the students in a class are those who don't want and can't. Since in the modern age, developing scientific morale, reflective and critical thinking, analysis ability, good thinking, and sound decision-making is by far more important than developing a brawny body, the future of the world will depend on the quality of the instruction we provide for our children. Mathematics and statistics classes must be revised and become learning environments to provide all students with suitable opportunities for learning more. Mathematics and statistics education must benefit from students' active involvement so that students can learn mathematics and statistics knowledge through comprehension, and build the new knowledge on the previous knowledge and experience.

The author maintains that the above-mentioned teaching methodology improves the students' attitude and beliefs. It makes them consider their own success as dependent on the group's success. Their self-testing skill is enhanced. They express their satisfaction with learning mathematics and statistics in a game-like setting in different ways. They have a sense of ownership to their learned knowledge, and obtain a high confidence in their mathematical abilities, and are not intimated by failure.

Students 'boredom with or fear of mathematics and its related subject matters can be drastically decreased by providing a class environment in which students are not afraid of making mistakes, do not receive the knowledge passively. Creating a constructivist class can enhance their involvement with the lesson. This is a fact that children especially students learn more when they enjoy the lesson more. In a constructivist setting, students themselves create the meaning and take the responsibility of learning. Traditional methods of teaching and assessing mathematics and also statistics does not allow students to have a pleasant experience with mathematics and statistics. This can lead to mathematophobia in which psychological barriers impede learning. In a constructivist class, since a student brings all his past experience and previous knowledge to the learning arena, teachers are recommended to pay attention and have some kind of relative acquaintance to the culture of the local communities and their interests and values as well as their attitude toward learning and mathematics and statistics. Ethnomathematics can work here and give the teachers hint how to sometimes relate mathematics and statistics to their local community and culture to enhance their interest and participation. 


\section{REFERENCES}

Popham, W. J. (2006). Needed: A dose of assessment literacy. Educational Leadership 63, 84-85.

Stiggins, R. J. (2001). The unfulfilled promise of classroom assessment. Educational Measurement: Issues and Practice, 20(3), 5-15.

Lefrancois Guy, R. (1999). Psychology for Teaching. Independence, KY: Cengage.

Carpenter, T. P., Fennema, E., Franke, M.L., Levi, L., \& Empson, S.B. (1999). Children's mathematics: Cognitively guided instruction. Portsmouth, NH: Heinemann.

National Council of Teachers of Mathematics. (2000). Principles and standards for School Mathematics. Reston, VA: National Council of Teachers of Mathematics (NCTM).

Steen, Lynn Arthur, ed. (2001). Mathematics and Democracy: the Case for Quantitative literacy. Princeton, NJ: National Council on Education and the Disciplines. 